\title{
Clarifying the Purported Association between Isotretinoin and Inflammatory Bowel Disease
}

\section{Steven S. Coughlin*}

Department of Epidemiology, Rollins School of Public Health, Emory University, Atlanta, GA

\author{
Received Date: December 19, 2014 \\ Accepted Date: March 23, 2015 \\ Published Date: March 27, 2015
}

"Corresponding authors: Steven S. Coughlin, Ph.D. Adjunct Professor, Department of Epidemiology, Rollins School of Public Health, Emory University, Atlanta, GA. 1437 Central Avenue, no. 910, Memphis, TN 38104, Tel: (404) 983-2524; E-mail: stevecatlanta@aol.com

Citation: Coughlin, S.S. Clarifying the Purported Association between Isotretinoin and Inflammatory Bowel Disease. (2015) J Environ Health Sci 1(2): 1-5.

Keywords: Acne vulgaris; Acne vulgaris/ drug therapy; Crohn's disease; Epidemiology; Inflammatory bowel disease; Post marketing; Product surveillance

\begin{abstract}
Isotretinoin was approved by the Food and Drug Administration (FDA) in 1982 and revolutionized acne therapy. Soon afterwards, case reports appeared suggesting a link between inflammatory bowel disease and use of isotretinoin. As reviewed in this article, an increasing number of case-control and prospective (cohort) studies have been reported that examined associations between use of isotretinoin and inflammatory bowel disease. Published epidemiologic studies of the use of isotretinoin and risk of Crohn's disease and ulcerative colitis vary according to whether the design was a case-control study or cohort study and by other important design differences. The strengths and limitations of the studies, such as their ability to control for important confounding variables (e.g., the severity of acne and use of antibiotics), also differ widely. Results across epidemiologic studies have been inconsistent and most studies have not found a strong association or a dose-response relationship. Based upon results from laboratory studies, several biological mechanisms have been proposed to account for either a positive (pathogenic) or inverse (protective) association between isotretinoin and inflammatory bowel disease. Although epidemiologic study findings are generally consistent with a correct temporal relationship (i.e., exposure to isotretinoin preceded the onset of inflammatory bowel disease), Crohn's disease and ulcerative colitis often have an insidious onset with some symptoms occurring well before a clinical diagnosis of inflammatory bowel disease is made. Taken overall, results from epidemiologic (case-control and cohort) studies completed to date do not show a consistent association between isotretinoin use and risk of inflammatory bowel disease. There is no clear evidence of a causal link.
\end{abstract}

\section{Introduction}

Isotretinoin is a vitamin A analog used to treat severe, recalcitrant nodulocystic acne, which can be disfiguring, result in permanent scarring, and adversely affect quality of life (Owen, 2014). The potential adverse effects of isotretinoin include dermatitis, increased sensitivity to sunburn, mucocutaneous cheilitis (dry lips), xerosis (dry skin), myalgia (muscle aches), and birth defects due to in utero exposure. Isotretinoin is a known teratogen and can cause fetal abnormalities (Prevost and English, 2013). Female patients of childbearing potential are monitored for contraception methods and pregnancy testing. A purported association between isotretinoin and inflammatory bowel disease has generated continuing controversy.

\section{Background}

Isotretinoin was approved by the Food and Drug Administration (FDA) in 1982 and revolutionized acne therapy (Owens, 2014). Soon afterwards, case reports appeared suggesting a link between inflammatory bowel disease and use of isotretinoin. Case reports, which do not establish causality, can be useful for generating research hypotheses that can then be tested in case-control or prospective epidemiologic studies.
However, case reports rarely provide proof of an association or causality as observations of case reports could have resulted from chance, uncontrolled confounding, recall bias, publication bias, and subjective presentation of case details (Crockett et al., 2009; Popescu and Bigby, 2013). Uncontrolled confounding by age is a possibility as the peak age of inflammatory bowel disease occurrence is in early adulthood and the peak age of isotretinoin use is ages 13 to 24 years (Crockett et al., 2009). Case reports of inflammatory bowel disease occurring among patients who received treatment for severe acne with isoretinoin do not rule out other causes (Popescu and Bigby, 2013). Reddy et al. (2006) reviewed adverse reports over the period 1997 to 2002 using data from the FDA MedWatch system. They found 85 reports of inflammatory bowel disease associated with use of isotretinoin. However, Stobaugh et al. (2013) found that disproportionate reporting by attorneys has seriously inflated the pharmacovigilance signal of isotretinoin-associated inflammatory bowel disease in the FDA Adverse Event Reporting System. Of 2,214 cases of inflammatory bowel disease with isotretinoin use, $1,944(87.8 \%$ were reported by attorneys, $132(6.0 \%)$ were reported by physicians, and $112(5.1 \%)$ were reported by consumers. In a review of published case reports and one case series on the use of isotretinoin and inflammatory bowel disease, Crockett et al. (2009) found that the results did not meet the Bradford Hill

Copy rights: O2015 Coughlin, S.S. This is an Open access article distributed under the terms of Creative Commons Attribution 4.0 International License. 
criteria for causality (Coughlin, 2010) and did not provide strong evidence of an association. The case reports identified in the literature review by Crockett et al. (2009) differed with respect to isotretinoin dose, duration of treatment before development of disease, whether disease developed on or off medication, and clinical presentation of disease.

\section{Results from Epidemiologic Studies}

An increasing number of case-control and prospective (cohort) studies have been reported that examined associations between use of isotretinoin and inflammatory bowel disease (Bernstein et al. 2009; Crockett et al., 2010; Etminan et al., 2013; Alhusayen et al., 2013; Racine et al., 2014). Bernstein et al. (2009) conducted a population-based case-control study using the Manitoba Inflammatory Bowel Disease Epidemiology Database, which is based upon data derived from Manitoba Health Administrative Databases. Cases of inflammatory bowel disease ( $\mathrm{n}=1,118$ Crohn's disease cases and 890 ulcerative colitis cases) diagnosed from April 2, 1995 to 2008 were matched to 10 randomly selected controls by age, gender, and postal area of residence (Berstein et al. 2009). The case definition had previously been validated and found to be highly specific. The controls were also matched to cases in such a manner that the controls were registered and living in Manitoba on the date of diagnosis of the respective inflammatory bowel disease case. Only cases and controls under the age of 40 years were included. The prevalence of inflammatory bowel disease was $1.2 \%$ among cases who had used isotretinoin and $1.1 \%$ among controls. Isotretinoin use was not associated with either Crohn's disease $(\mathrm{OR}=1.15,95 \% \mathrm{CI}$ $0.61,2.02)$ or ulcerative colitis ( $\mathrm{OR}=1.16,95 \%$ CI $0.56,2.20)$. The inclusion of exposures to isotretinoin occurring many years before the diagnosis of inflammatory bowel disease may have biased the results toward the null. Crockett et al. (2010) conducted a case-control study using the PharMetrics Patient-Centric Database, a United States insurance claims database. Three controls were selected for each case, matching on age, gender, geographical region, health plan, and length of enrollment. A total of 8,189 cases of inflammatory bowel disease were identified along with matched 21,832 controls. Isotretinoin use during the 12 month exposure period occurred in 24 cases and 36 controls (Crockett, 2010). The results from this study suggested that isotretinoin use in the preceding 12 months was associated with ulcerative colitis (odds ratio $(\mathrm{OR})=4.36,95 \%$ confidence interval $(\mathrm{CI}) 1.97$, 9.66) but not Crohn's disease ( $\mathrm{OR}=0.68,95 \% \mathrm{CI} 0.28,1.68)$. A positive dose-response relation was observed in that increasing dose of isotretinoin was associated with elevated risk of ulcerative colitis (OR per $20 \mathrm{mg}$ increase in dose $=1.50,95 \%$ CI 1.08 , 2.09). Neither of these case-control studies controlled for acne severity or use of antibiotics. Most patients treated with isotretinoin have failed to respond adequately to at least one course of oral antibiotics (Femia and Vleugels, 2013). A further limitation is that cases of inflammatory bowel disease were not validated against original medical records (Thakrar and Robinson, 2011). The strengths of these case-control studies (Crockett et al., 2010; Bernstein et al., 2009) include the use of health administrative data which reduces the likelihood of recall bias.

In a meta-analysis of published and unpublished findings from epidemiologic studies of the relationship of isotreti- noin and risk of inflammatory bowel disease conducted through 2012, Etminan et al. (2013) found no increase in the risk for inflammatory bowel disease, including ulcerative colitis or Crohn's disease, associated with use of isotretinoin. The pooled odds ratios obtained from the meta-analysis did not show an association between use of isotretinoin and either Crohn's disease (pooled $\mathrm{OR}=0.75,95 \% \mathrm{CI} 0.46,1.24$ ) or ulcerative colitis (pooled $\mathrm{OR}=$ $1.61,95 \%$ CI $0.88,2.95$ ) (Etminan et al., 2010). The meta-analysis included results from the author's nested case-control study (Etminan et al., 2013). Using data from the IMS Life Link health plan claims database, which included claims from 102 health plans in the U.S., the authors formed a cohort of women aged 18 to 46 years who had received at least 1 oral contraceptive prescription from May 1, 2001 through December 31, 2009. Twenty controls were selected for each case while matching on age and data of diagnosis. A total of 2,159 cases of inflammatory bowel disease were identified (1,056 with ulcerative colitis and 1,103 with Crohn's disease) along with 43,180 controls. Only 10 cases $(0.46 \%)$ and 191 controls $(0.44 \%)$ were exposed to isotretinoin. Adjustment was made for a variety of potential confounding factors including use of oral tetracycline antibiotics and acne. The adjusted OR for Crohn's disease was 1.10 (95\% CO $0.44,2.70)$ and the adjusted OR for ulcerative colitis was $1.10(95 \%$ CI $0.44,2.70)$. Although the authors used the same health claims database as that previously used by Crockett et al. (2010), they nested their cohort in a population of women taking combined oral contraceptives. The advantage of this approach is that it limits confounding by indication (since acne is an indication for both combined oral contraceptives and isotretinoin treatments) and confounding by use of combined oral contraceptives (combined oral contraceptives have been associated with inflammatory bowel disease in some studies) (Etminan et al., 2013). However, no adjustment was made for cigarette smoking or family history of inflammatory bowel disease.

Alhusayen et al. (2013) reported results from a 12-year population-based retrospective cohort study that utilized health care records from about 4.5 million residents of British Columbia, Canada aged 12 to 29 years. A total of 46,922 patients had been treated with isotretinoin, 184,824 patients had been treated with topical acne medications, and 1,526,946 were untreated and served as the referent group. The authors identified patients who had no history of inflammatory bowel disease five years before the index date. Each study participant was observed for up to 1 year following the index date to identify inflammatory bowel disease. The design of the study allowed treated and untreated patients to enter the analysis more than once; each entry was considered a discrete observation (Alhusayen et al., 2013). Of 11,408 patients who had a first medical encounter for inflammatory bowel disease, 87 patients had been treated with isoretinoin, 316 had been treated with topical acne medication, and 11,005 were in the reference group. No association was observed between treatment with isotretinoin and inflammatory bowel disease $(\mathrm{OR}=1.14,95 \%$ CI $0.92,1.41)$, except in a subset of patients aged 12 to 19 years $(\mathrm{OR}=1.39,95 \% \mathrm{CI} 1.03,1.87)$. A similar pattern was observed with topical acne medication, suggesting that there may be an association between acne itself and inflammatory bowel disease rather than with isotretinoin treatment (Alhusayen et al., 2013). A strength of this study is that the authors adjusted for use of tetracycline and erythromycin, and 
any physician visit in the year prior to the index date. With respect to limitations, no adjustment was made for family history of inflammatory bowel disease or smoking status. In addition, a single code was used for inflammatory bowel disease as the outcome measure (Alhusayen et al., 2013).

Racine et al. (2014) conducted a nation-wide case-control study of isotretinoin and risk of inflammatory disease using data from the French National Insurance system between January 1, 2008 and December 31, 2010. The system includes health information for over 50 million people who comprise about $76 \%$ of the entire French population. A total of 7,593 cases of inflammatory bowel disease (3,187 ulcerative colitis cases, 4,397 Crohn's disease cases, and 9 cases of indeterminate colitis) and 30,372 controls were included. The cases and controls were matched on year of birth, gender, year of enrollment (2009 or 2010), and follow-up duration. A total of 15 ulcerative colitis cases $(0.5 \%), 11$ Crohn's disease cases $(0.3 \%)$, and 140 controls $(0.4 \%)$ were exposed to isotretinoin. Drug exposure was recorded in the calendar year preceding the date of diagnosis for cases and the date of inclusion for controls. Isotretinoin exposure was not associated with ulcerative colitis $(\mathrm{OR}=1.36,95 \% \mathrm{CI} 0.76$, 2.45 ) but there was a suggestion that it was inversely associated with Crohn's disease based upon results from this one study (OR $=0.45,95 \%$ CI $0.24,0.85$ ). Similar results were obtained by the authors in analyses restricted to individuals aged less than 40 years, or when adjusting for other acne treatments such as topical retinoids, oral tetracycline, and erythromycin (Racine et al., 2014). There was no statistically significant does-effect relationship between daily dose, cumulative dose, or total duration of isotretinoin use, and either Crohn's disease or ulcerative colitis. The strengths of this study include its population-based design and the factor that the authors adjusted for use of tetracycline, erythromycin, and other acne treatments. No adjustment was made for cigarette smoking, however.

Rashtak et al. (2014) conducted a single center retrospective study of inflammatory bowel disease and isotretinoin use in Olmsted County, Minnesota. The electronic medical records of patients who were primarily seeking acne treatment were reviewed for isotretinoin exposure. The participants included 1,078 patients. The exposed group included patients with confirmed prior isotretinoin exposure $(n=576)$, and the nonexposed group were defined as patients who never received isotretinoin or received it after the diagnosis of IBD $(n=502)$. Both groups were comparable by race, prior systemic antibiotic use, and systemic tetracycline use (Rashtak et al., 2014). Inflammatory bowel disease developed less frequently in the isotretinoin-exposed group vs. the nonexposed group ( $0.9 \%$ vs $2.6 \%$; $\mathrm{P}=.03$; unadjusted $\mathrm{OR}=0.33 ; 95 \% \mathrm{CI}, 0.12,0.93 ; \mathrm{P}=.04)$. The negative association between isotretinoin exposure and IBD remained after adjusting for sex $(\mathrm{OR}=0.28 ; 95 \% \mathrm{CI}, 0.10,0.80$; $\mathrm{P}=.02)$ and for sex and non-acne indication $(\mathrm{OR}=0.28 ; 95 \%$ CI, $0.10,0.79 ; \mathrm{P}=.02)$. The generalizability of these findings to other populations (for example, non-white patients in other parts of the United States) is uncertain.

\section{Discussion}

Published epidemiologic studies of the use of isotretinoin and risk of Crohn's disease and ulcerative colitis, which are summarized in Table 1, vary according to whether the design was retrospective (case-control studies) or prospective (cohort study) and by other important design differences. The strengths and limitations of the studies, such as their ability to control for important confounding variables, also differ widely. The population-based case control study by Crocket et al. (2010) was the first to show a positive association between isotretinoin and ulcerative colitis. Based upon results from just that one epidemiologic study, at least three of the Hill critiera for causality (strength of the association, biological gradient or dose-response relationship, and correct temporal relationship, i.e., exposure to isotretinoin preceded the onset of inflammatory bowel disease) are met. However, results across epidemiologic studies have been inconsistent and most studies have not found a strong association or a dose-response relationship. The specificity of the association is debatable but specificity is often considered to be the weakest of the Hill criteria (Crockett, 2009). There is no clear evidence of a causal link between isotretinoin and IBD based upon epidemiologic studies.

Table 1. Published epidemiologic studies of isotretinoin use and inflammatory bowel disease, 2009-2014.

\begin{tabular}{|c|c|c|c|c|}
\hline Study & Sample & Design & Results & Limitations \\
\hline $\begin{array}{l}\text { Bernstein et } \\
\text { al., } 2009\end{array}$ & $\begin{array}{l}\text { Cases of IBD }(n=2,008) \text { from the } \\
\text { Manitoba IBD Epidemiology Database } \\
\text { matched to } 10 \text { randomly selected con- } \\
\text { trols, aged }<40 \text { years. }\end{array}$ & $\begin{array}{l}\text { Case-control } \\
\text { study }\end{array}$ & $\begin{array}{l}\text { Isotretinoin use was not associated with } \\
\text { either Crohn's disease }(\mathrm{OR}=1.15,95 \% \\
\text { CI } 0.61,2.02) \text { or ulcerative colitis }(\mathrm{OR}= \\
1.16,95 \% \text { CI } 0.56,2.20) \text {. }\end{array}$ & $\begin{array}{l}\text { The inclusion of isotreinoin exposures } \\
\text { occurring many years before the diag- } \\
\text { nosis of IBD may have biased the re- } \\
\text { sults towards the null. IBD cases were } \\
\text { not validated against original medical } \\
\text { rcords. No adjustment was made for } \\
\text { acne severity or use of antibiotics. }\end{array}$ \\
\hline $\begin{array}{l}\text { Crockett et } \\
\text { al., } 2010\end{array}$ & $\begin{array}{l}8,189 \text { IBD cases identified using a U.S. } \\
\text { insurance claims database and } 21,832 \\
\text { matched controls. }\end{array}$ & $\begin{array}{l}\text { Case-control } \\
\text { study }\end{array}$ & $\begin{array}{l}\text { Isotretinoin use in the preceding } 12 \\
\text { months was associated with ulcerative } \\
\text { colitis (odds ratio (OR) }=4.36,95 \% \\
\text { confidence interval (CI) } 1.97,9.66 \text { ) but } \\
\text { not Crohn's disease (OR }=0.68,95 \% \text { CI } \\
0.28,1.68 \text { ). }\end{array}$ & $\begin{array}{l}\text { IBD cases were not validated against } \\
\text { original medical rcords. No adjust- } \\
\text { ment was made for acne severity or } \\
\text { use of antibiotics. }\end{array}$ \\
\hline $\begin{array}{l}\text { Etminan et } \\
\text { al., } 2013\end{array}$ & $\begin{array}{l}2,159 \text { cases of IBD from a cohort of } \\
\text { women aged } 18 \text { to } 46 \text { years who had re- } \\
\text { ceived oral contraceptives and } 43,180 \\
\text { matched controls, identified using a } \\
\text { U.S. insurance claims database. }\end{array}$ & $\begin{array}{l}\text { Nested case-con- } \\
\text { trol study }\end{array}$ & $\begin{array}{l}\text { The adjusted OR for Crohn's disease was } \\
1.10(95 \% \text { CO } 0.44,2.70) \text { and the ad- } \\
\text { justed OR for ulcerative colitis was } 1.10 \\
(95 \% \text { CI } 0.44,2.70) \text {. }\end{array}$ & $\begin{array}{l}\text { No adjustment was made for family } \\
\text { history of IBD or cigarette smoking. }\end{array}$ \\
\hline
\end{tabular}




\begin{tabular}{|c|c|c|c|c|}
\hline $\begin{array}{l}\text { Alhusayen et } \\
\text { al. } 2013\end{array}$ & $\begin{array}{l}46,922 \text { patients who had been treat- } \\
\text { ed with isotretinoin, } 184,824 \text { patients } \\
\text { who had been treated with topical acne } \\
\text { medications, and } 1,526,946 \text { who were } \\
\text { untreated (referent group), identified } \\
\text { using health care records from about } \\
4.5 \text { million residents of British Colum- } \\
\text { bia, Canada. }\end{array}$ & $\begin{array}{l}\text { Population-based } \\
\text { retrospective co- } \\
\text { hort study }\end{array}$ & $\begin{array}{l}\text { No association was observed between } \\
\text { treatment with isotretinoin and inflamma- } \\
\text { tory bowel disease (OR }=1.14,95 \% \text { CI } \\
0.92,1.41) \text {, except in a subset of patients } \\
\text { aged } 12 \text { to } 19 \text { years (OR }=1.39,95 \% \text { CI } \\
1.03,1.87) \text {. }\end{array}$ & $\begin{array}{l}\text { No adjustment was made for family } \\
\text { history of IBD or smoking status. A } \\
\text { single code was used for IBD. }\end{array}$ \\
\hline $\begin{array}{l}\text { Racine et al., } \\
2014\end{array}$ & $\begin{array}{l}\text { A total of } 7,593 \text { cases of IBD and } \\
30,372 \text { matched controls, identified } \\
\text { using data from the French National } \\
\text { Insurance system. }\end{array}$ & $\begin{array}{l}\text { Population-based } \\
\text { case-control study }\end{array}$ & $\begin{array}{l}\text { Isotretinoin exposure was not associated } \\
\text { with ulcerative colitis }(\mathrm{OR}=1.36,95 \% \\
\text { CI } 0.76,2.45) \text { but was inversely associat- } \\
\text { ed with Crohn's disease }(\mathrm{OR}=0.45,95 \% \\
\text { CI } 0.24,0.85) \text {. }\end{array}$ & $\begin{array}{l}\text { No adjustment was made for cigarette } \\
\text { smoking. }\end{array}$ \\
\hline $\begin{array}{l}\text { Rashtak et } \\
\text { al., } 2014\end{array}$ & $\begin{array}{l}\text { The electronic medical records of pa- } \\
\text { tients who were primarily seeking } \\
\text { acne treatment were reviewed for } \\
\text { isotretinoin exposure. The participants } \\
\text { included } 1,078 \text { patients in Olmsted } \\
\text { County, Minnesota. The exposed group } \\
\text { included patients with confirmed prior } \\
\text { isotretinoin exposure }(n=576) \text {, and the } \\
\text { nonexposed group were defined as pa- } \\
\text { tients who never received isotretinoin } \\
\text { or received it after the diagnosis of IBD } \\
(n=502) \text {. }\end{array}$ & $\begin{array}{l}\text { Retrospective sin- } \\
\text { gle center study }\end{array}$ & $\begin{array}{l}\text { Both groups were comparable by race, } \\
\text { prior systemic antibiotic use, and system- } \\
\text { ic tetracycline use. Inflammatory bowel } \\
\text { disease developed less frequently in the } \\
\text { isotretinoin-exposed group vs. the non- } \\
\text { exposed group ( } 0.9 \% \text { vs } 2.6 \% ; \mathrm{P}=.03 \text {; } \\
\text { unadjusted OR }=0.33 ; 95 \% \mathrm{CI}, 0.12 \text {, } \\
0.93 ; \mathrm{P}=.04) \text {. The negative association } \\
\text { between isotretinoin exposure and IBD } \\
\text { remained after adjusting for sex (OR = } \\
0.28 ; 95 \% \mathrm{CI}, 0.10,0.80 ; \mathrm{P}=.02) \text { and for } \\
\text { sex and non-acne indication }(\mathrm{OR}=0.28 \text {; } \\
95 \% \mathrm{CI}, 0.10,0.79 ; \mathrm{P}=.02) \text {. }\end{array}$ & Uncertain generalizability \\
\hline
\end{tabular}

A number of biological mechanisms have been proposed to account for either a positive (pathogenic) or inverse (protective) association between isotretinoin and inflammatory bowel disease (Crockett et al. 2009; Alhusayen et al., 2013; Femia and Vleugels, 2013), as summarized in Table 2. Additional biological pathways have been proposed to account for a positive association between acne and inflammatory bowel disease (Femia and Vleugels, 2013). These proposed biological mechanisms and pathways are based upon findings from laboratory studies (Norris et al, 1987; Osanai et al., 2007; Kang et al., 2007; Mucida et al., 2007; Mora et al., 2009). Previous authors have noted that epidemiologic studies have suggested that there may be a positive association between antibiotic use and inflammatory bowel disease (Alikhan et al., 2011).

Table 2. Possible biological mechanisms for a positive (pathogenic) or inverse (protective) association between isotretinoin and inflammatory bowel disease.

\begin{tabular}{|l|}
\hline Possible biological mechanisms for a positive (pathogenic) association \\
\hline Stimulation of natural killer (NK) cells and apoptosis (Mora et al. 2009) \\
\hline Cytokine regulation (Guruvayoorappan \& Kuttan. 2008) \\
\hline Inhibition of neutrophil chemotaxis (Alhusayen et al. 2013) \\
\hline Differentiation of B-cells (Femia \& Vleugels 2013) \\
\hline $\begin{array}{l}\text { Disrupted glycoprotein synthesis and epithelial tissue growth (Femia \& Vleu- } \\
\text { gels 2013) }\end{array}$ \\
\hline
\end{tabular}

Possible biological mechanisms for an inverse (protective) association

Inhibition of proinflammatory interleukin-17 producing T-helper cells $(\mathrm{Mu}-$ cida et al. 2007)

Enhanced barrier function of intestinal epithelium (Osanai et al. 2007)

Up-regulation of T-regulatory cells (Crockett et al. 2009)

In summary, results from laboratory studies appear to support the biologic plausibility of either a positive or inverse association between use of istotretinoin and inflammatory bowel disease. In addition, epidemiologic study findings are generally consistent with a correct temporal relationship. However, it has not been established that use of istotretinoin triggers the onset of Crohn's disease or ulcerative colitis, both of which often have an insidious onset with some symptoms occurring well before a clinical diagnosis of inflammatory bowel disease is made. Most epidemiologic studies have not found a association or a dose-response relationship. Taken overall, results from epidemiologic studies completed to date do not show a consistent association between isotretinoin use and risk of either Crohn's disease or ulcerative colitis and the causality of these associations has not been established.

Acknowledgement: The author has received consulting fees from Hoffman-LaRoche, Ltd.

\section{Reference}

1. Alikhan, A., Henderson, G.P., Becker, L., et al. Acne treatment and inflammatory bowel disease: what is the evidence? (2011) J Am Acad Dermatol 65(3): 650-654.

2. Alhusayen, R.O., Juurlink, D.N., Mamdani, M.M., et al. Isotretinoin use and the risk of inflammatory bowel disease: a population-based cohort study. (2013) J Invest Dermatol 133(4): 907-912.

3. Bernstein, C.N., Nugent, Z., Longobardi, T., et al. Isotretinoin is not associated with inflammatory bowel disease: a population-based case-control study. (2009) Am J Gastroenterol 104(11): 2774-2778.

4. Coughlin, S.S. Causal Inference and Scientific Paradigms in Epidemiology. (2010) Bentham Science Publishers, Ltd., 56-64.

5. Crockett, S.D., Gulati, A., Sandler, R.S., et al. A causal association between isotretinoin and inflammatory bowel disease has yet to be established. (2009) Am J Gastroenterol 104(10): 2387-2393.

6. Crockett, S.D., Porter, C.Q., Martin, C.F., et al. Isotretinoin use and the risk of inflammatory bowel disease: a case-control study. (2010) Am J Gastroenterol 105(9): 1986-1993.

7. Etminan, M., Bird, S.T., Delaney, J.A., et al. Isotretinoin and risk for inflammatory bowel disease. A nested case-control study and meta-analysis of published and unpublished data. (2013) JAMA Dermatol 149(2): 216-220.

8. Femia, A.N., Vleugels, R.A. Toward improved understanding of a potential association between isotretinoin and inflammatory bowel dis- 
ease. (2013) J Invest Dermatology 133(4): 866-868.

9. Guruvayoonrappan, C., Kuttan, G. 13 cis-retinoic acid regulates cytokine production and inhibitsangiogenesis by disrupting endothelial cell migration and tube formation. (2008) J Exp Ther Oncol 7(3): 173-182. 10. Kang, S.G., Lim, H.W., Andrisani, O.M., et al. Vitamin A metabolites induce gut-homing FoxP3+ regulatory T cells. (2007) J Immunol 179(6): 3724-3733.

11. Owen, C.E. Treating acne with high-dose isotretinoin. (2014) JAMA 311(20): 2121-2122.

12. Osanai, M., Nishikiori, N., Murata, M., et al. Cellular retinoic acid bioavailability determines epithelial integrity: role of retinoic acid receptor alpha agonists in colitis. (2007) Mol Pharmacol 71(1): 250-258. 13. Mora, J.R., von Andrian, U.H. Role of retinoic acid in the imprinting of gut-homing IgA-secreting cells. (2009) Semin Immunol 21(1): 28-35. 14. Mucida, D., Park, Y., Kim, G., et al. Reciprocal TH17 and regulatory $\mathrm{T}$ cell differentiation mediated by retinoic acid. (2007) Science 317(5835): 256-260.

15. Norris, D.A., Osborn, R., Robinson, W., et al. Isotretinoin produces significant inhibition of monocyte and neurtrophil chemotaxis in vivo in patients with cystic acne. (1987) J Invest Dermatol 89(1): 38-43.

16. Popescu, C.M., Bigby, M. The weight of evidence on the association of isotretinoin use and the development of inflammatory bowel disease. (2013) JAMA Dermatol 149(2): 221-222.
17. Popescu, C.M., Popescu, R. Isoretinoin therapy and inflammatory bowel disease. (2011) Arch Dermatol 147(6): 724-729.

18. Prevost, N., English, J.C. Isotretinoin: update on controversial issues. (2013) J Pediatr Adolesc Gynecol 26(5): 290-293.

19. Racine, A., Cuerq, A., Bijon, A., et al. Isotretinoin and risk of inflammatory bowel disease: a case control study from the French National Health Insurance System. (2012) Gastroenterology 142(5,Suppl 1): S88. 20. Racine, A., Cuerq, A., Bijon, A., et al. Isotretinoin and risk of inflammatory bowel disease: a French nationwide study. (2014) Am J Gastroenterol 109(4): 563-569.

21. Rashtak, S., Khaleghi, S., Pittelkow, M.R., et al. Isotretinoin exposure and risk of inflammatory bowel disease. (2014) JAMA Dermatol 150(12): 1322-1326.

22. Reddy, D., Siegel, C.A., Sands, B.E., et al. Possible association between isotretinoin and inflammatory bowel disease. (2006) Am J Gastroenterol 101(7): 1569-1573.

23. Stobaugh, D.J., Deepak, P., Ehrenpreis, E.D. Alleged isotretinoin-associated inflammatory bowel disease: disproportionate reporting by attorneys to the Food and Drug Administration Adverse Event Reporting System. (2013) J Am Acad Dermatol 69(3): 393-398.

24. Thakrar, T.B., Robinson, N.J. Isotretinoin use and the risk of inflammatory bowel disease. (2011) Am J Gastroenterol 106(5): 1000-1002. 